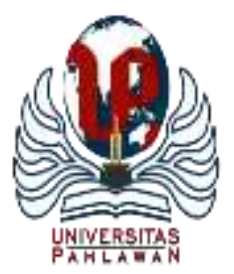

Edukatif : Jurnal Ilmu Pendidikan Volume 4 Nomor 1 Tahun 2022 Halm 372 - 379

EDUKATIF: JURNAL ILMU PENDIDIKAN

Research \& Learning in Education

https://edukatif.org/index.php/edukatif/index

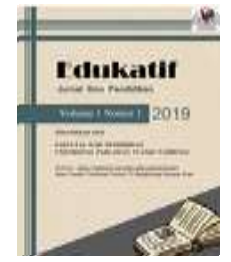

\title{
Persepsi Pelaku Terhadap Bullying dan Humor
}

\author{
Hartika Sari Butar Butar ${ }^{1 凶}$, Yeni Karneli ${ }^{2}$ \\ Universitas Negeri Padang, Indonesia ${ }^{1,2}$ \\ E-mail : $\underline{\text { hsbutar212@ gmail.com }}^{1}$, yenikarneli@ fip.unp.ac.id ${ }^{2}$
}

\begin{abstract}
Abstrak
Perbedaan persepsi mengakibatkan meningkatnya kasus bullying yang terjadi di sekolah. Siswa memiliki persepsi yang berbeda mengenai perilaku bullying yang mereka lakukan. Penelitian ini bertujuan untuk mendeskripsikan persepsi pelaku tentang bullying dan humor. Penelitian ini termasuk penelitian kuantitatif dengan menggunakan metode deksriptif, memiliki 421 populasi dan 60 sampel pada siswa kelas XII SMK Negeri 3 Padang tahun ajaran 2021/2022. Pengumpulan data dilakukan dengan menggunakan skala model likert dan semantik deferensial. Hasil penelitian ini secara keseluruhan menunjukkan bahwa persepsi pelaku tentang bullying di SMK Negeri 3 Padang berada pada kategori sedang $(66,21 \%)$, dapat dilihat dari masingmasing aspek, yaitu bullying fisik berada pada kategori sedang $(56,61 \%)$, bullying verbal berada di kategori tinggi $(73,89 \%)$, bullying sosial dan relasional berada pada kategori sedang $(64,21 \%)$. Sedangkan persepsi pelaku terhadap humor berada pada kategori tinggi (80,76\%). Berdasarkan hasil tersebut memberikan gambaran bahwa persepsi pelaku tentang perilaku bullying yang dilakukan dinilai sebagai humor/candaan ditandai dengan tingginya tingkat humor pada perilaku bullying. Hasil penelitian ini memberikan gambaran akan pentingnya peranan Guru Bimbingan Konseling dalam memberikan layanan informasi, bimbingan kelompok, konseling kelompok dan konseling individual guna untuk mereduksi dan mencegah perilaku bullying.
\end{abstract}

Kata Kunci: Persepsi pelaku,bullying,humor.

\begin{abstract}
Differences in perceptions of bullying problems that occur in schools. Students have different perceptions about their bullying behavior. This study aims to describe the perpetrator's perception of bullying and humor. This research includes quantitative research using descriptive methods, has a population of 421 and 60 samples in class XII students of SMK Negeri 3 Padang in the academic year 2021/2022. Data was collected using a Likert scale model and differential semantics. The results of this study as a whole indicate that the perpetrator's perception of bullying at SMK Negeri 3 Padang is in the medium category (66.21\%), it can be seen from each aspect, namely physical bullying is in the category (56.61\%), verbal bullying are in the high category (73.89\%), social and relational bullying are in the medium category (64.21\%). Meanwhile, the perpetrator's perception of humor is in the high category (80.76\%). Based on these results, it illustrates that the perpetrator's perception of bullying behavior is assessed as humor/joke marked by the level of humor in bullying behavior. The results of this study provide an overview of the importance of the role of Guidance Counseling Teachers in providing information services, group guidance, group counseling and group counseling in order to reduce and prevent bullying behavior.
\end{abstract}

Keywords: Perception of perpetrator, bullying, humor

Copyright (c) 2022 Hartika Sari Butar Butar, Yeni Karneli

$\triangle$ Corresponding author

Email : hsbutar212@gmail.com

DOI : https://doi.org/10.31004/edukatif.v4i1.1843

ISSN 2656-8063 (Media Cetak)

ISSN 2656-8071 (Media Online)

Edukatif : Jurnal Ilmu Pendidikan Vol 4 No 1 Tahun 2022 p-ISSN 2656-8063 e-ISSN 2656-8071 


\section{PENDAHULUAN}

Bullying merupakan tindakan yang dilakukan seseorang untuk menyakiti, menghina, menekan, menjatuhkan mental dan mengontrol orang lain dengan cara melakukan kekerasan sehingga membuat korban menerima segala bentuk perlakuan dari pelaku bullying (Yonita \& Karneli, 2019). Bullying akan sangat merugikan korban dan tingkat bullying pada remaja yang terlibat sebagai pelaku dan korban bullying sekitar 20-35\% (Muslim et al., 2019).

Data yang dimiliki Organisation for Economic Cooperation and Development (OECD) mengatakan bahwa siswa yang mengalami bullying di Indonesia sebesar $41,1 \%$ dan menjadi peringkat kelima tertinggi dari 78 Negara yang paling banyak mengalami bullying (Jayani, 2019). Komisi Perlindungan Anak Indonesia (2016) mengidentifikasi data kasus berdasarkan klaster siswa pelaku bullying dari tahun 2011-2016 sebesar 430 dan pada tahun 2011-2017 sebesar 26 ribu kasus bullying (Setyawan, 2017). Data KPAI yang disampaikan oleh Novianto (2018) terdapat 41 atau 25,5\% pelaku bullying pada tahun 2018 dan pada tahun 2019 pelaku bullying masih tinggi dan berada diposisi kedua sebanyak 153 atau 39\% kasus (Listyarti, 2019). Sejalan dengan yang disampaikan oleh Pusat Pelayanan Terpadu Pemberdayaan Perempuan dan Anak (P2TP2A) yang ada di Provinsi Sumatera Barat yang menyatakan bahwa mereka sudah melayani 55 kasus pada 2018 dan pada bulan Februari tahun 2019 sebanyak 19 kasus kekerasan, pelecehan seksual hingga bullying yang melibatkan anak-anak dan perempuan (Fajri, 2019).

Berdasarkan hasil wawancara dengan siswa dan Guru BK, penulis mendapatkan permasalahan bullying terjadi di kelas XII. Permasalahan yang terjadi seperti: mengejek dan mengganggu salah satu teman hingga korban menangis dan menjadi bahan tawaan teman yang lain, sengaja memberi nama julukan yang kurang baik kepada korban sehingga membuat korban menjadi ocehan teman-temannya, mengambil jajanan milik korban dengan paksaan, menyuruh dan membentak korban ketika meminta tolong dan membanting barang yang berada di sekitar korban ketika sedang marah agar ditakuti oleh teman-teman yang lain. Hasil wawancara yang dilakukan merupakan tindakan bullying, seperti yang dikatakan oleh (Coloroso, 2007) bahwa bullying fisik merupakan penindasan fisik seperti memukul, mencekik, menyikut, meninju, menendang, menggigit, memiting, mencakar, serta meludahi anak yang ditindas hingga ke posisi yang menyakitkan, serta merusak dan menghancurkan pakaian serta barang-barang milik anak yang tertindas dan Chakrawati (2015) mengungkapkan bullying verbal adalah menyakiti seseorang dengan ucapan, misalnya mengejek, mengganti namanya dengan nama lain yang kurang baik, mencaci, menggosip, memaki, membentak dan sebagainya.

Remaja merupakan generasi penerus bangsa yang diharapkan mampu memberikan sumbangansumbangan yang positif bagi bangsa dan negara (Sriwahyuningsih et al., 2016). Siswa Sekolah Menengah Kejuruan (SMK) merupakan siswa yang memasuki masa remaja, remaja cenderung membawa dampak psikologis dan dampak fisiologis, para remaja masih mengalami ketidaktentuan dalam mencari identitas seperti ingin berkuasa dan merasa hebat seperti menjadi pelaku bullying, cenderung berpikir pendek dan ingin cepat dalam memecahkan berbagai masalah dalam kehidupan (Restu, 2013). Remaja yang menjadi korban bullying lebih beresiko mengalami masalah mental. Masalah mental yang mungkin akan dialami siswa ialah mengalami depresi, kegelisahan dan sulit tidur yang akan terbawa hingga dewasa, rasa tidak aman saat berada di lingkungan sekolah, penurunan semangat belajar dan prestasi akademis (Zakiyah et al., 2017). Sedangkan dampak bullying yang paling jelas adalah kesehatan fisik, seperti luka, lebam, sakit kepala, sakit tenggorokan, flu, batuk, sakit dada dan bahkan kematian (Yonita \& Karneli, 2019).

Sejalan dengan hasil penelitian yang dilakukan Takizawa, Maughan \& Arseneault (2014) menyatakan bahwa siswa yang di bullying di masa kecil akan mendapatkan dan meningkatkkan tekanan biologis pada usia 23 sampai 50 tahun. Korban yang sering di bullying akan lebih tinggi tingkat depresinya dan terus beresiko melebar pada rentang sosial, kesehatan dan ekonomi yang buruk. Faktor yang mendorong siswa tetap melakukan bullying adalah persepsi perilaku, kebanyaan siswa yang menganggap bahwa bullying bukan menjadi masalah melainkan sebuah humor yang biasa terjadi di sekolah. Anehnya ada beberapa dari mereka 
yang mengatas namakan pertemanan dalam setiap kejadian bullying yang berlangsung, bahkan karna mereka sering mengganggu temannya mereka merasa hubungan pertemanan mereka lebih erat lagi padahal yang dilakukan mereka adalah bullying (Wawancara Siswa di SMK Negeri 3 Padang).

Masih banyak yang menganggap bullying di kalangan siswa yang mendapat pemakluman (Budiman, 2020). Bullying menjadi lebih sering dilakukan karena minimnya respon, orang yang melihatnya lebih sering membiarkan dan beranggapan bahwa tindakan tersebut sepele padahal sangat beresiko. Pelaku bullying akan mempersepsikan bahwa perilakunya justru mendapatkan pembenaran bahkan memberinya identitas sosial (Sari \& Azwar, 2017). Adanya pengalaman yang terjadi pada diri pelaku sehingga membentuk persepsi untuk melakukan bullying (Suharnan, 2005), seseorang akan berperilaku sesuai dengan apa yang dipersepsikannya, namun setiap orang akan memiliki persepsi yang berbeda-beda (Rahmat, 2004).

Persepsi merupakan salah satu faktor yang mempengaruhi perilaku bullying. Persepsi bullying umumnya juga sering disamakan dengan humor. Nubatonis (2018) mengungkapkan bahwa saat ini, bercanda dan bullying seakan-akan malah tidak memiliki perbedaan sama sekali atau sama saja, sehingga ketika satu pihak melakukan bullying maka si pelaku akan menganggapnya sebagai hal biasa, hanya bercanda, padahal faktanya korban merasa sudah terbullying. Bullying bahkan dijumpain disudut daerah tempat tinggal dan sekolah karena banyaknya remaja yang mengindikasikan bullying sebagai bahan candaan agar suasana pertemanan tidak monoton (Soraya \& Rizaldi, 2015) dan ada juga siswa yang melihat temannya mengejek, mengolok-ngolok atau mendorong namun perlakuan itu dianggap sebagai hal biasa terjadi dan menganggapnya sebatas relasi sosial antar teman, padahal hal tersebut adalah bentuk perilaku bullying (Sucipto, 2012). Sejalan dengan yang dijelaskan oleh Rachman (2019) bahwa siswa sudah terbiasa saling mengejek sebagai bahan candaan yang kerap dianggap bahan candaan yang telah melewati batas dan mengarah ke perilaku bullying. Batas yang begitu tipis antara bercanda dan bullying membuat pelaku bullying juga kerap salah mempersepsikan, seperti bercanda yang dianggap lucu dan tidak menyakiti orang lain namun bisa menjadi bullying jika bermaksud menyakiti orang lain atau bahkan membuat orang lain merasa tersakiti saat sedang bercanda. Sejalan dengan yang dikatakan oleh Rahmanadji (2007) bahwa candaan menjadi sarana untuk seseorang dalam berkomunikasi dengan orang lain, membuat orang lain tersenyum dan tertawa karena sesuatu yang menggelikan, mempesona, aneh dan identik dengan kelucuan, akan tetapi tidak menyudutkan seseorang ataupun menjadikan orang lain sebagai bahan candaan yang membuatnya merasa tersakiti karena candaan dilakukan untuk menghibur orang lain bukan menyakiti.

Hal ini memperlihatkan bahwa terdapat perbedaan persepsi siswa terhadap perilaku bullying di setiap sekolah. Bullying sebagai stimulus akan diorganisasikan dan diinterpretasikan berbeda oleh siswa, perbedaan hasil persepsi setiap orang dapat terjadi karena persepsi bersifat individual (Walgito, 2004). Ketika persepsi siswa terhadap perilaku bullying berbeda dengan siswa yang lain, maka perilaku bullying yang terjadi di sekolah juga bisa berbeda-beda. Selain itu, apabila siswa tidak menyadari bahwa perilakunya merupakan perilaku bullying maka pencegahan terhadap terjadinya bullying menjadi terhambat. Kesadaran siswa terhadap terjadinya perilaku bullying dan akibat yang ditimbulkan dari perilaku tersebut menjadi salah satu kunci untuk mengurangi korban bullying di masa mendatang. Fenomena-fenomena inilah yang membuat peneliti sangat tertarik untuk melakukan sebuah penelitian tentang persepsi pelaku terhadap bullying dan humor.

\section{METODE PENELITIAN}

Penelitian yang dilakukan merupakan penelitian deskriptif kuantitatif yang akan mendeskripsikan persepsi pelaku terhadap bullying dan humor. Subana (2001) mengemukakan bahwa penelitian deskriptif merupakan penelitian yang bertujuan untuk menjelaskan, meringkaskan kondisi dengan berbagai situasi atau berbagai variabel yang timbul dimasyarakat berdasarkan apa adanya sesuai dengan kenyataan. Selanjutnya Irianto (2004) menjelaskan bahwa penelitian deskriptif bertujuan mendeskriptifkan atau menjelaskan suatu hal sebagaimana adanya secara aktual. 
Berkaitan dengan ini Yusuf (2013) menyatakan bahwa penelitian deskriptif akan memfokuskan peneliti menjajaki kebelakang, kemasa peristiwa itu terjadi, apa yang menjadi penyebab suatu peristiwa atau kejadian yang menjadi objek penelitian, dengan membandingkan fenomena pada kelompok atau beberapa kelompok. Populasi dalam penelitian ini yaitu seluruh siswa XII SMK Negeri 3 Padang tahun ajaran 2021/2022 sebanyak 421 orang. Jumlah sampel 60 siswa yang dipilih menggunakan teknik purposive sampling. Pengumpulan data dilakukan dengan menggunakan skala model Likert dan semantik deferensial.

\section{HASIL DAN PEMBAHASAN PENELITIAN}

Penelitian ini dimaksudkan untuk melihat persepsi siswa tentang bullying dan humor, yang mana penelitian dilakukan pada kelas XII di SMK Negeri 3 Padang. Sangat penting untuk memiliki pengetahuan mengenai bullying dan humor, baik untuk diri sendiri maupun untuk orang sekitar yang belum mengetahui apa yang dimaksud dengan bullying dan humor. Persepsi merupakan proses pengamatan pengorganisasian, penginterpretasian terhadap stimulus yang diterima oleh organisme atau individu sehingga menjadi sesuatu yang berarti dan merupakan aktivitas yang integrated dalam diri individu (Walgito, 2004). Berdasarkan hasil analisis pengolahan instrumen bullying, maka dispesifikasikan menjadi 5 kategori tingkat bullying yang ditinjau dari karakteristik bullying secara umum, dapat dilihat pada tabel 1 tentang bullying dan tabel 2 tentang humor.

Hasil penelitian ini cukup menarik karena pada perilaku bullying berada dalam kategori sedang dan pada tingkat humor berada pada kategori tinggi.

Tabel 1. Persepsi Pelaku Terhadap Bullying

\begin{tabular}{ccccc}
\hline \multicolumn{5}{c}{ Persepsi pelaku terhadap bullying secara keseluruhan } \\
\hline Interval & $\%$ & Kategori & F & $\%$ \\
\hline$\geq 89$ & $\geq 84$ & ST & 1 & 1,67 \\
\hline $72-88$ & $68-83$ & $\mathrm{~T}$ & 20 & 33,33 \\
\hline $55-71$ & $52-67$ & $\mathrm{~S}$ & 34 & 56,67 \\
\hline $38-54$ & $36-51$ & $\mathrm{R}$ & 5 & 8,33 \\
\hline$\leq 37$ & $\leq 35$ & $\mathrm{SR}$ & 0 & 0 \\
\hline 5 & & 60 & 100 \\
\hline \multicolumn{5}{c}{ Persepsi pelaku terhadap bullying berdasarkan sub variabel } \\
\hline \multicolumn{5}{c}{ Bullying Fisik } \\
\hline Bullying Verbal & & $56,61 \%$ \\
\hline Bullying Sosial dan Relasional & $73,89 \%$ \\
\hline
\end{tabular}

Pada Tabel 1 memperlihatkan persepsi tentang bullying yang dimiliki pelaku secara umum berada pada kategori Sedang dengan jumlah 34 siswa (56,67\%). Meskipun begitu, terdapat 20 siswa yang memiliki persepsi tentang bullying berada pada kategori Tinggi (33,33\%). Hasil analisis juga menunjukkan bahwa 5 siswa memiliki persepsi tentang bullying pada kategori Rendah sebanyak 5 siswa (8,33\%). Sedangkan pada kategori Sangat Tinggi terdapat 1 siswa $(1,66 \%)$ yang memiliki persepsi tentang bullying dan tidak ada siswa yang memiliki persepsi mengenai bullying pada kategori Sangat Rendah. Kemudian hasil pendistribusian instrumen menunjukkan bahwa siswa cenderung memiliki permasalahan dalam hal bullying verbal sebesar $73,89 \%$, kemudian masalah pada bullying sosial dan relasional sebesar $64,28 \%$ dan masalah terakhir pada bullying fisik yaitu sebesar $56,61 \%$. 
Sejalan dengan hasil penelitian diparagraf sebelumnya maka hasil penelitian menunjukkan bahwa pelaku memiliki persepsi yang berbeda tentang bullying. Tingkat persepsi mengenai bullying juga berada pada kategori sedang, hal ini menadakan bahwa pelaku memiliki persepsi bullying menjadi hal yang sudah biasa terjadi di sekolah dan jika dibiarkan maka pelaku bullying akan terus meningkat. Hal ini menandakan bahwa pentingnya upaya untuk meningkatkan pemahaman siswa mengenai bullying. Wiyani (2012) bahwa bullying merupakan suatu perilaku negatif yang dilakukan pelaku untuk mengganggu, mengusik dan membatasi orang lain untuk melakukan sesuatu berulang yang bermaksud menyebabkan ketidak senangan atau menyakitkan oleh orang lain, baik satu atau beberapa orang secara langsung terhadap seseorang yang tidak mampu melawannya.

Penindasan fisik merupakan jenis perilaku bullying yang paling tampak dan paling berbahaya dibandingkan bentuk bullying yang lainnya. Pembullyan ini akan mengakibatkan cidera pada anggota tubuh dan cenderung pada tindakan-tindakan kriminal yang lebih serius. Bentuk dari bullying fisik diantaranya menendang, mencubit, menampar, meludahi, memukul, merusak barang, memalak, menggigit, memiting, mencakar dan melilit telinga. Sedangkan kata-kata adalah alat yang dapat mematahkan semangat seseorang, kekerasan verbal adalah bentuk penindasan yang paling umum digunakan baik bagi anak perempuan maupun anak laki-laki. Penindasan verbal dapat berupa julukan nama, mengolok-ngolok, berkata kasar, kritik kejam, penghinaan dan segala sesuatu yang dapat menyakiti melalui ucapan langsung dengan seseorang. Penindasan yang sering terjadi ialah seorang siswa yang dengan sengaja untuk membuat temannya jadi bahan omongan temannya yang lain dan sengaja untuk menjelekkan temannya sendiri. Penindasan sosial dan relasional adalah pelemahan harga diri seseorang melalui pengabaian, pengucilan, pengecualian, penyingkiran dan mempermalukan yang merupakan penindasan yang terkuat. Perilaku ini juga membuat seseorang menjadi jelek dan dijauhi oleh lingkungannya dengan merusak nama baiknya (Coloroso, 2007).

Hasil penelitian juga menemukan data tingkat humor berdasarkan perilaku bullying yang terjadi, sebagai berikut.

Tabel 2 (Persepsi Pelaku Terhadap Humor)

\begin{tabular}{ccccr}
\hline \multicolumn{5}{c}{ Persepsi pelaku terhadap humor secara keseluruhan } \\
\hline Interval & $\%$ & Kategori & F & $\%$ \\
\hline$\geq 89$ & $\geq 84$ & ST & 26 & 43,33 \\
\hline $72-88$ & $68-83$ & $\mathrm{~T}$ & 25 & 41,67 \\
\hline $55-71$ & $52-67$ & $\mathrm{~S}$ & 5 & 8,33 \\
\hline $38-54$ & $36-51$ & $\mathrm{R}$ & 3 & 5 \\
\hline$\leq 37$ & $\leq 35$ & $\mathrm{SR}$ & 1 & 1,67 \\
\hline \multicolumn{5}{c}{ Rata-rata } \\
\hline \multicolumn{5}{c}{ Persepsi pelaku terhadap humor berdasarkan sub } \\
variabel & 60 & 100 \\
\hline \multicolumn{5}{c}{ Bullying Fisik } \\
\hline Bullying Verbal \\
\hline Bullying Sosial dan Relasional & $83,89 \%$ \\
\hline
\end{tabular}

Berdasarkan Tabel 2 memperlihatkan persepsi tentang humor yang dimiliki pelaku secara umum berada pada kategori Sangat Tinggi dengan jumlah 26 siswa $(43,33)$. Meskipun begitu, terdapat 25 siswa yang memiliki persepsi tentang humor berada pada kategori Tinggi (41,67\%), Hasil analisis juga menunjukkan bahwa 5 siswa yang memiliki kategori Sedang (8,33\%). Sedangkan kategori Rendah sebanyak 3 siswa (5\%), dan diikutin pada kategori Sangat Rendah sebanyak 1 siswa (1,67\%). Selanjutnya pada hasil pendistribusian 
instrumen menunjukkan bahwa siswa cenderung memiliki tingkat humor yang sangat tinggi terutama pada perilaku bullying verbal sebesar $85,74 \%$, kemudian bullying sosial dan relasional sebesar $83,89 \%$ dan terakhir pada bullying fisik yakni sebesar 70,17\%. Hal ini menunjukkan bahwa sebagian besar siswa mempersepsikan bahwa perilaku bullying yang selama ini mereka lakukan hanya sebagai humor/bercanda, ditandai dengan tingkat humor yang tinggi.

Tindakan bullying yang dilakukan hanya sekedar membuat lelucon untuk menghibur teman-teman yang lainnya, namun yang menjadi korbannya adalah siswa yang terlihat lemah dibandingkan pelaku sehingga membuat aksi pembullyian berlanjut (Sejiwa, 2008). Humor dan candaan sebenarnya memainkan peranan penting dalam pola interaksi anak-anak khsususnya di sekolah. Meski negatif, humor dan candaan mereka gunakan untuk meningkatkan status penerimaan di depan teman-teman mereka (Humaniora, 2020).

Perilaku bullying yang dipertanyakan dalam angket juga terlihat bahwa para siswa hanya menganggap perilaku bullying itu hanya sebatas candaan/humor. Kemungkinan besar adalah persepsi siswa yang menganggap perilaku bullying itu sebagai candaan yang membuat kasus bullying tinggi dan belum terselesaikan sampai sekarang ini. Untuk itu hendaknya sama-sama dalam meningkatkan batasan-batasan antara bullying dan humor agar terhindarnya kasus-kasus berikutnya. Sejalan dengan yang disampaikan oleh Rossa \& Efendi (2021) ketika kita bercanda maka haruslah membuat orang yang dibecandai tetap merasa nyaman, berusaha untuk tidak memojokkan, tidak memuaskan satu pihak saja misalnya hanya membuat dirinya tertawa namun tidak membuat orang yang dibecandainya tertawa.

Membully sering dianggap sebagai candaan sehingga pelakunya "dimaklumi" dan tidak mendapat hukuman (Deviyana, 2017). Tidak sedikit pelaku bullying yang tidak sadar bahwa mereka sudah melakukan aksi perundungan karena menganggap hanya sebuah candaan. Namun jika sebuah perilaku sudah berkelanjutan atau mengintimidasi orang yang lebih lemah ini sudah dimaksudkan dalam perundungan. Terlepas dari apa yang diakui sebagai niat pelakunya (Bulu et al., 2019). Ada batasan yang jelas antara bullying dan bercanda, jika yang dimaksud adalah bercanda dengan teman maka semua pihak harus samasama merasa senang dan menikmati tanpa ada dua pihak yang terpisah antara pelaku dan korban. pelaku yang dimaksudkan disini ialah pihak yang dianggap kuat dan korban ialah pihak yang dianggap lemah. Perilaku akan dianggap bullying ketika salah satu pihak yang diajak berinteraksi merasa tersakiti, baik secara fisik dan perasaan (Sulaiman, 2017).

\section{KESIMPULAN}

Persepsi setiap orang akan berbeda dalam melihat peristiwa bullying, begitu pula seorang pelaku yang berbeda dalam mempersepsikan tindakan bullying yang dilakukannya. Bullying yang terjadi di sekolah memiliki kategori sedang yang berarti bahwa siswa masih melakukan perilaku bullying di sekolah, siswa lebih sering melakukan bullying secara verbal, dari 60 siswa yang menjadi sampel hendaknya lebih dipantau untuk kejadian yang mendatang namun bukan berarti siswa diluar dari 60 orang ini tidak terpantau, karena bullying akan terjadi pada siapapun baik sebagai pelaku maupun korban. Untuk itu agar sama-sama menjaga agar tidak terjadi lagi, para siswa hendaknya mengetahui batasan-batasan antara bullying dan humor agar lebih memudahkan untuk menurunkan kasus-kasus maupun perilaku bullying yang terjadi. Siswa harus lebih mampu dalam menghargai orang lain dan menimbulkan keempatian terhadap sesama. Dari hasil penelitian ini mengungkapkan bahwa para siswa hanya menganggap perilaku bullying sebagai humor, untuk itu para siswa diharapkan agar tidak bermain-main lagi dan mengatasnamakan bercanda diatas perilaku yang membuat oranglain merasa tersakiti dan tidak nyaman. Hal ini yang menjadi penguat dalam tindakan pencegahan terjadinya bullying. Kebanyakan dari siswa menganggap bahwa perlakuan bullying yang terjadi di sekolah sebagai interaksi antar teman maupun hal yang biasa terjadi sebagai menghidupkan suasana di kelas namun para siswa tidak menyadari hal yang dilakukan menjadikan korban merasa terhina, marah dan sakit hati hingga ada yang mengalami sakit di fisik dan secara mental. Untuk itu sebagaimana hasil dari penelitian ini 
bisa digunakan untuk landasan dari pemberian layanan dalam program BK di sekolah untuk mengurangi kasus bullying dengan cara memberi pengarahan dan bimbingan pada siswa yang menjadi pelaku maupun korban bullying.

\section{DAFTAR PUSTAKA}

Budiman, A. (2020). Bullying Picu Gangguan Jiwa Anak Mayoritas Terjadi Di Lingkungan Sekolah. Jawa Pos Radar Solo. Https://Radarsolo.Jawapos.Com/Read/2019/12/15/170291/Bullying-Picu-GangguanJiwa-Anak

Bulu, Y., Maemunah, N., \& Sulasmini. (2019). Faktor-Faktor Yang Mempengaruhi Perilaku Bullying Pada Remaja Awal. Nursing News, Https://Publikasi.Unitri.Ac.Id/Index.Php/Fikes/Article/Download/1473/1047

Chakrawati, F. (2015). Bullying Siapa Takut? (Panduan Untuk Mengatasi Bullying). Solo: Tiga Ananda.

Coloroso, B. (2007). Stop Bullying: Memutus Rantai Kekerasan Anak Dari Prasekolah Hingga Smu. Jakarta: Pt. Serambi Ilmu Semesta.

Deviyana, N. (2017). Bercanda Sering Jadi Dalih Pelaku Bullying. Https://Www.Medcom.Id/Rona/Keluarga/4kzezwyk-Bercanda-Sering-Jadi-Dalih-Pelaku-Bullying.

Fajri, E. (2019). Rumah Aman Anak Dp3a Sumbar Siap Layani Korban Kejahatan Seksual. Klikpositif. Http://Klikpositif.Com/Baca/46777/Rumah-Aman-Anak-Dp3a-Sumbar-Siap-Layani-Korban-KejahatanSeksual

Humaniora. (2020). Bullying Dan Selera Humor Anak-Anak Kita Yang Rendah. 13 Kompasiana.

Irianto, A. (2004). Statistik: Konsep Dasar, Aplikasi, Dan Pengembangannya Edisi Keempat. Jakarta: Prenadamedia Group.

Jayani, D. H. (2019). Persentase Murid Yang Mengalami Bullying. Https://Databoks.Katadata.Co.Id/Datapublish/2019/12/12/Pisa-Murid-Korban-Bully-Di-IndonesiaTertinggi-Kelima-Di-Dunia

Kpai. (2016). Rincian Data Kasus Berdasarkan Klaster Perlindungan Anak 2011-2016. In Komisi Perlindungan Anak Indonesia (Kpai). Https://Bankdata.Kpai.Go.Id/Tabulasi-Data/Data-Kasus-PerTahun/Rincian-Data-Kasus-Berdasarkan-Klaster-Perlindungan-Anak-2011-2016

Listyarti, R. (2019). Kpai Terima 153 Aduan Kasus Kekerasan Anak Pada 2019. Gatracom. Https://Www.Gatra.Com/Detail/News/464092/Milenial/Kpai-Terima-153-Aduan-Kasus-KekerasanAnak-Pada-2019

Muslim, Neviyarni, \& Karneli Y. (2019). Effectiveness Of Cognitive Behavior Therapy In Improving Students ' Understanding Of Bullying. Journal Of Educational And Learning Studies, 2(2), 94-100.

Novianto, R. D. (2018). Catatan Kpai Bidang Pendidikan: Kasus Bullying Paling Banyak. Sindonews.Com.

Nubatonis, T. (2018). Bercanda Atau "Bully"? Identifikasi Kebiasaan Pergaulan Dalam Generasi Milenial. Kompasiana. Https://Www.Kompasiana.Com/Tonny49426/5bf32042bde575026b605232/BercandaAtau-Bully-Mengidentifikasi-Kebiasaan-Pergaulan-Dalam-Generasi-Milenial?Page=All

Rachman, A. (2019). Tanda Anak Jadi Korban Bullying Disekolah. Https://Www.Sehatq.Com/Artikel/CaraMembedakan-Bercanda-Dan-Bullying

Rahmanadji, D. (2007). Sejarah, Teori, Jenis, Dan Fungsi Humor. Bahasa Dan Seni, 35(2), 213-221.

Rahmat, J. (2004). Psikologi Komunikasi. Bandung: Remaja Rosdakarya.

Restu, Y. (2013). Studi Tentang Perilaku Agresif Siswa Di Sekolah. Jurnal Ilmiah Konseling, 2(1), 243-249.

Rossa, V., \& Efendi, D. A. (2021). Bullying Pegawai Kpi Disebut Hanya Candaan, Ini Beda Candaan Dan 
Bullying Menurut Pakar. Suara.Com. Https://Www.Suara.Com/Lifestyle/2021/09/07/232038/BullyingPegawai-Kpi-Disebut-Hanya-Candaan-Ini-Beda-Candaan-Dan-Bullying-Menurut-Pakar?Page=All

Sari, Y. P., \& Azwar, W. (2017). Fenomena Bullying Siswa: Studi Tentang Motif Perilaku Bullying Siswa Di Smp Negeri 01 Painan, Sumatera Barat. Jurnal Pengembangan Masyarakat Islam, 10(2), 333-367.

Sejiwa. (2008). Bullying: Mengatasi Kekerasan Di Sekolah Dan Lingkungan Sekitar Anak. Jakarta: Penerbit Pt Grasindo.

Setyawan, D. (2017). Kpai Terima Aduan 26 Ribu Kasus Bully Selama 2011-2017. Komisi Perlindungan Anak Indonesia (Kpai). Https://Www.Kpai.Go.Id/Berita/Kpai-Terima-Aduan-26-Ribu-Kasus-BullySelama-2011-2017

Soraya, A., \& Rizaldi, Y. (2015). Kampanye Sosial Bahaya Bullying Dalam Pergaulan Remaja. Jurnal Proporsi, 1(1), 77-89.

Sriwahyuningsih, V., Yusuf, A. M., \& Dahranis. (2016). Hubungan Prasangka Dan Frustrasi Dengan Perilaku Agresif Remaja. Jppi (Jurnal Penelitian Pendidikan Indonesia), 2(2), 38-51.

Subana, M. (2001). Dasar-Dasar Penelitian Ilmiah. Bandung: Pustaka Setia.

Sucipto. (2012). Bullying Dan Upaya Meminimalisasikannya. Psikopedagogia, 1(1).

Suharnan. (2005). Psikologi Kognitif. Surabaya: Srikandi.

Sulaiman, M. R. (2017). Bullying Vs Bercanda, Dimana Batas Perbedaannya? Detikhealth. Https://Health.Detik.Com/Berita-Detikhealth/D-3565525/Bullying-Vs-Bercanda-Di-Mana-BatasPerbedaannya

Takizawa, Maughan, \& Arseneault. (2014). Adult Health Outcomes Of Childhood Bullying Victimization: Evidence From A Five-Decade Longitudinal British Birth Cohort. Am J Psychiatry, 171(7), 777-784.

Walgito, B. (2004). Pengantar Psikologi Umum. Yogyakarta: Rajawali Perss.

Wiyani, N. A. (2012). Save Our Children From School Bullying. Yogyakarta: Ar-Ruzz Media.

Yonita, E. N., \& Karneli, Y. (2019). The Effectiveness Of The Cognitive Behavior Modification Approach With Group Settings To Reduce Bullying Behavior. Jurnal Neo Konseling, 1(3), 1-7.

Yusuf, A. . (2013). Metode Penelitian: Kuantitatif, Kualitatif Dan Penelitian Gabungan. Kencana.

Zakiyah, Humaedi, \& Santoso. (2017). Faktor Yang Mempengaruhi Remaja Dalam Melakukan Bullying. Jurnal Penelitian \& Ppm, 4(2), 129-389. 